\title{
3D Modelling Of Customized Lasts Based On Anthropometric Data Acquired From 3D Foot Scanning - One Study Case
}

Mariana Costea ( $\sim$ mariana.costea@academic.tuiasi.ro)

Universitatea Tehnica Gheorghe Asachi https://orcid.org/0000-0003-4924-739X

Aura Mihai

Universitatea Tehnica Gheorghe Asachi din lasi

Arina Seul

Universitatea Tehnica Gheorghe Asachi din lasi

\section{Research Article}

Keywords: shoe last, footwear, 3D modelling, manufacturing personalized lasts

Posted Date: May 3rd, 2021

DOI: https://doi.org/10.21203/rs.3.rs-394662/v1

License: () (i) This work is licensed under a Creative Commons Attribution 4.0 International License. Read Full License 


\section{Abstract}

Designing and manufacturing personalized lasts are the first steps in obtaining the right fitted footwear for various users, especially for sport or/and medical purposes. The accurate dimensional relationship between foot and last represents the key element for this activity. The critical shape of the last should always be determined by the shape of the foot and the cumulative relationship between lengths, widths, heights and girths, whatever method is used, Some corrections and constraints must always be considered because the shoe-last is not identical to the foot. The foot anthropometric measurements are modified based on biomechanical constraints and technological limitations and they are interactively transformed into last's dimensions by using 3D modelling. The present study brings together the modern scanning technique with the new methodology for modifying a reference last, and it is aimed to explore the philosophy of re-designing functional lasts. It also tests and highlights the limits of the actual methodology for shoe-last virtual prototyping based on anthropometric data acquired from one commercially available 3D foot scanning system.

\section{Introduction}

When purchasing footwear, consumers are looking for two main features: style and comfort. Footwear products that do not correspond dimensionally to the foot shape, and also do not take over the foot modifications while standing or walking, represent the main cause for prevalence and evolution of structural and functional foot anomalies (Dahmen R et.al. 2001, Williams A.E. et.al. 2011). Moreover, the health of the entire body, as well as the human performance, could be affected. Customized footwear for different uses, including the medical and sports ones, is an important market niche (Uccioli L. 2006, Jones J., and Wimpenny D. 2009). Personalized footwear based on customized lasts could solve some of the foot problems related to sizing, poor fitting or perceived a lack of comfort (Lee Au E.Y. et.al 2011, Liu S. et.al 2011, Luximon A. et.al 2012).

The footwear shape and its inner space are both influenced by the shape and dimensions of the technological lasts (Chung-Shing W., 2010). Often, several physical prototypes that go through a series of adaptations and adjustments are required. The virtual prototype can be created, analysed and modified long before producing a physical prototype. This technology diminishes the time for testing the physical prototype; also other designing problems may be resolved in the virtual prototyping stage. The main advantages are given by reducing time and costs for trials of the new products (Wang Z. et all, 2009).

There is an increasing demand for industrial applications of systems digitizing the human body, and there are markedly available innovative solutions regarding affordable imaging techniques, such as laser scanners, multiple video cameras, motion capture systems or projector-camera sets. The 3D images are transformed into digital forms, and the process of designing new products includes new stages, such as modelling and simulation for the virtual prototype. Virtual prototyping suggests new opportunities both for researchers and for customized footwear businesses (Telfer S. and Woodburn J., 2010). While the manual measuring of the foot introduces errors caused by the skills of the person who takes the measurements, the automatic measurement from a scanning device could offer error-free data (Witana C.P et.al. 2006).

Nowadays, the lasts can be rapidly designed due to the recent developments in computer-aided design (CAD) technologies (Wang J. et.al 2011). The computerized method consists in the 3D modelling of the last; this method has the advantage of simulating the new shape before a physical last prototype is manufactured. When a last is interactively or/and automatically modified, the new changes are carried out while the designers visualize their models at every step; thus, the entire shoe-last designing process is less time consuming. Because of some limits in using commercially available CAD systems, most of the shoe-last designers still prefer manual methods (Luximon A., Luximon Y, 2009). The mixed techniques for designing new lasts use combinations between computer-aided designing based on modelling software and manual methods based on lasts construction type grouping and/or 2D templates (Sederberg, T.W. 1986). Regardless of the method, important design features determine how the required fitting conditions are achieved; also, the dimensional design restrictions should refer to the technological constraints of lasts manufacturing (Luximon A., Luximon Y, 2009).

Designing new lasts and re-designing existing ones are based on foot anthropometric. There are certain restrictive factors affecting the last's shape and its dimensions: acceptable limits of foot tightening by footwear, modification of foot dimensions while walking (biomechanics), footwear constructive type, physical and mechanical properties of materials, and footwear manufacturing technology. Also, one has to consider the general design requirements of the footwear. The footwear is comfortable when, throughout its inner volume and dimensions, it allows the foot to achieve its protective, biomechanical and orthopaedic functions (Sikyung K. et.al 2007, Pastina M., Mihai A., 2010; Pastina M., Mihai A., 2011; lonesi et. all, 2014).

\section{Method}

The paper presents one case study, but the hereby described method, as well as the developed methodology for analyzing the final results of the modelling process, can be replicated and applied for any new study case. The high degree of interaction between practitioner/designer and its computer, as well as the high level of customization are the main advantages of this re-designing process. Five working stages are considered in order to obtain the modified last: 1) scanning of the foot; 2) positioning of the anatomical points on foot; 3) measurement/calculation of the main anthropometric measurements; 4) comparison of the foot against the reference last; 5) modification of the last according to the foot shape.

\subsection{Scanning of the foot}

The studied case refers to a subject having visibly identified foot problems that ask for a careful interpretation of the design features based on anthropometric data, biomechanics and orthopaedic requirements. The subject (47-year-old, female) agreed to be studied on a voluntary basis. She has been previously diagnosed with arthritis and the results of clinical analysis of her feet allowed establishing the correct premises for designing a customized last according to the identified risk of developing a more severe arthritic foot. Several initial stages of structural modification related to arthritic feet have been identified, in this case, especially in the forefoot area. Thus, the subject presents incipient stages of modification on the first toe (Hallux-Valgus) on both feet and, visible differences in the height of the first toe of the right foot and the left foot.

Page 2/13 
The subject's foot is scanned by using a 3D foot scanning system; respectively the INFOOT USB Standard Model IFU-S-01, provided with eight progressive 1/4' CCD cameras and four laser instruments, class $1 \mathrm{M}$. INFOOT scans a foot and positions the anatomical landmarks, which are used to measure automatically/calculate up to 20 measuring items. It scans the 3D foot form and the anatomical points in about 10 seconds per foot, and the dimensions and angles are automatically calculated and viewed in a few seconds. The subject stands with one barefoot inside the scanner and one foot outside the scanner, and the entire mass of the subject is equally distributed on both feet.

The scanned foot data can be used for foot morphological analysis, footwear/last selection, and also for designing new lasts or re-designing existing ones. The scanned data have the points cloud format, wireframe or solid format, and they are saved as FBD binary data that gives both the 3D foot shape and the position of the anatomical points. The binary file can also be exported by a specific INFOOT software module (for example File Converter) as *.csv, *.dxf, *.vrml or *.stl formats. These exported formats could be imported into different modelling or designing software. For this study, the OrthoLast modelling software from Delcam Crispin has been used.

\subsection{Positioning of the anatomical points on foot}

Accurate positioning of the anatomical points influences the value of anthropometric parameters. For the hereby-presented study case, the anatomical points mapping (Fig. 1) suggested by the scanner's producer - INFOOT used (*** INFOOT website). The landmarks are automatically given by software in few seconds. Because several problems and structural modifications against normal foot have been identified for this case, each anatomical point is checked, and it is moved (if necessary) in its right position. Also, each transversal section is checked and corrected in case shape distortions occurred during scanning. Even if the scanning process takes several seconds, the correction process can take a long time. The commercially available scanning systems recognize the anatomical points for normal feet; in the case of feet having anomalies, this standard facility is less useful. Therefore, the accurateness in measurements taken for customized footwear can be affected by introducing huge errors regarding positioning the anatomical points (Sarghie et al., 2013).

\subsection{Measurement/calculus of the main anthropometric measurements}

The applied anthropometry into footwear industry aims to measure the foot. The foot measurements are assessed through precisely defined points that are called anatomical points. The anatomical points are some protuberances of the foot skeleton or its joints, and they are becoming well-shaped limits of the soft tissues. Several basic measurements are mentioned (Xiong S., et.al. 2008) for characterizing the foot dimensions and, therefore, its anthropometric. The longitudinal measurements (lengths of the foot) represent the distances from the heel extreme point (landing point or nearby it) to a series of precise anatomical points (for example, 1 st or 2 nd toe, instep point, 1 st metatarsal head and 5 th metatarsal head, etc.). These distances are measured up along the longitudinal axis of the foot. There are different opinions among specialists regarding the right position for this axis (Reel S., et.al. 2010, Chantelau E., and Gede A., 2002, Nikolaidou M.E., and Boudolos K.D. 2006). To keep the same reference as for the longitudinal axis of the last, the longitudinal axis of the foot is given in this study by the line that joins the heel centre with the head of 2nd metatarsal bone (Pastina et al., 2012). The transversal measurements are represented by widths and girths. The widths are measured on the outline of the foot or the footprint, perpendicularly on the foot's longitudinal axis or in line with ball direction. The girths are circumferences of foot measured up according to with previous defined sectional planes on metatarsal heads, instep, heel, ankle, etc. The heights represent the vertical distance measured up from the footing surface. These dimensions are measured through precisely defined points that are called anatomical points. The anatomical points are some protuberances of the skeleton or the joints, and they are becoming well-shaped limits of the soft tissues.

Fifteen anthropometric measurements (Fig. 2) are significant dimensions from footwear designer point of view: FL-Foot Length, FL5-Foot Length to 5th metatarsal head, FL1-Foot Length to 1st metatarsal head, FBW-Foot Ball Width, FLW-Foot Lateral Width, FAW-Foot Arch Width, FHW-Foot Heel Width, FBG-Foot Ball Girth, FIG-Foot Instep Girth, FHC-Foot Heel Circumference, FHB-Foot Height to top of Ball girth, FHI-Foot Height to Instep point, FHL-Foot Height to Lateral malleolus, FHM-Foot Height to Medial malleolus, FHT-Foot Height to 1st Toe joint.

Due to lack of generalized, universal accepted rules for taking measurements on foot/last, as well due to the need of standardized models for transforming the anthropometric data into dimensional parameters of last, the foot anthropometry applied to designing well-fitted footwear has been found quite difficult (Bertram H., 2011).

\subsection{Comparing the foot against the reference last}

The reference last, which is imported from an existing database, is subject to an interactively comparing process against the scanned foot. Following simplified hypotheses were considered for this study: the selected reference last has appropriate size towards subject's foot length, it has low heel height, and it has rounded toe. On these lines, by using the Compare module of OrthoLast-Delcam Crispin software, the two 3D shapes (foot and last) were brought together on the same screen. The reference last and the foot are successively moved and rotated to align them in the same plane (Fig. 3).

When the two forms (last and foot) are correctly positioned, the face centre line of the foot should match with the face centre line of the last and the centre back line of the foot should match with the back centre line of the last. This process is somehow time-consuming, and it requires from designer to have strong visual abilities for correct perspectives on 3D forms moving into 2D space available on flat computer screens. At this point, any further technological developments on similar software could be very useful regarding making this process in an automatic manner, just with several corrections at the end.

\subsection{Modifying the reference last toward the foot shape}

A shoe-last designer is using various foot anthropometrical data that are transformed into constructive parameters of the last. Loot length, ball width and ball girth, instep and heel region girths, toe height, toe spring and heel height have been identified as most important factors affecting designs of shoe-lasts (Cheng F.T.and Perng D.B, 1999, Bertram H., 2011). Our study intends to analyze several more aspects and to extend the number of constructive parameters to highlight their importance and influence. Thus, using Delcam OrthoLast software the following parameters were modified and measured: Stick Length (SL), Lateral Width (LW), Bottom Length (BL), Ball Girth (BG), Ball Upper Girth (BUG), Ball Width Curved (BWC), Ball Width Linear (BWL), Instep Upper Girth (IUG), 
Instep Width Curved (IWC), Instep Width Linear (IWL), Short Heel Curved (SHC), Heel Width (HW), Heel Height (HH), Heel Counter (HC), Entrance Width (EW), Toe Spring (TS), Toe Length (TL), Toe Thickness (TT), Arch Curve (AC), Arch Width (AW). Figure 4 illustrates the methodology for measuring the herebymentioned parameters.

The technique of transforming an initial 3D structure into a new one, namely Free-From Deformation of Solid Geometric Models, represents one of the graphic procedures that allow for modifying a 3D structure by moving the basic points/nodes of its grid (Sederberg, T.W. 1986, Mochimaru M. and Kouchi M. 2011; Dumitras C., Cozminca I., 2008). Mochimaru M. et.al (2000) used this method for building new deformed grids suitable for grading the lasts. In our study, one structure (the last) represents the grid that will be interactively modified by moving precise points, and the other structure (the foot) represents the comparing form. The last and the foot are being compared until they are overlapping in as many points as possible. The two 3D shapes have different appearances: draft solid for foot and gridded frame for last. By overlapping, it can be seen the differences between the foot and the last. Therefore, the last will be modified in precisely selected areas (Fig. 5).

The last is modified acting on nine typical dimensional parameters, namely interactively modified parameters: SL, LW, BG, IUG, HW, HH, HC, TS, and TT. These parameters have been selected based on an initial analysis of the need for modification according to with the subject's foot. The other dimensional parameters that also describe the modified shape of the last represent the outcome-modified parameters, and they are BL, BUG, BWC, BWL, IWC, IWL, SHC, EW, $T L, A C, A W$. On each step, one single parameter from the first category is interactively modified. The modification upon one parameter is affecting all studied parameters that allow for collecting series of data to be statistically analyzed.

\section{Results}

When wearing shoes, the foot is constrained to modify its shape and dimensions among certain admissible limits of tightening. The constructive dimensional parameters of last provide limits of tightening the foot by footwear. As a result, a lower level of tightening the foot by footwear that will reduce the risk of high pressures on concrete foot surfaces is one functional requirement in this study case (Andrews K.L. 2011, Dahmen R., et.al. 2001).

Table 1 shows the obtained data from 3D interactive modifications on dimensional parameters by following up nine successive steps. Each step is based on the results obtained in the previous step. When one parameter is modified, the entire range of the studied parameters is collected. While the modelling process advances, there can be determined paired relationships among sets of parameters that characterize the shape of last at each step of modification. Also, the set of dimensional parameters for the resulting last could be compared against the initial one. 
Table 1

Values for interactively modified parameters and for outcome modified parameters

\begin{tabular}{|c|c|c|c|c|c|c|c|c|c|}
\hline $\begin{array}{l}\text { Parameters } \\
\text { of the last }\end{array}$ & $\begin{array}{l}\text { Reference } \\
\text { Last } \\
(\mathrm{mm})\end{array}$ & $\begin{array}{l}\text { 1st step of } \\
\text { modification- } \\
\text { on SL (mm) }\end{array}$ & $\begin{array}{l}\text { 2nd step of } \\
\text { modification- } \\
\text { on LW (mm) }\end{array}$ & $\begin{array}{l}\text { 3rd step of } \\
\text { modification- } \\
\text { on BG (mm) }\end{array}$ & $\begin{array}{l}\text { 4th step of } \\
\text { modification- } \\
\text { on IUG (mm) }\end{array}$ & $\begin{array}{l}\text { 5th step of } \\
\text { modification- } \\
\text { on } \mathrm{HH}(\mathrm{mm})\end{array}$ & $\begin{array}{l}\text { 6th step of } \\
\text { modification- } \\
\text { on } \mathrm{HW}(\mathrm{mm})\end{array}$ & $\begin{array}{l}\text { 7th step of } \\
\text { modification- } \\
\text { on } \mathrm{HC}(\mathrm{mm})\end{array}$ & $\begin{array}{l}\text { 8th step of } \\
\text { modificatiol } \\
\text { on TS (mm) }\end{array}$ \\
\hline \multicolumn{10}{|c|}{ Interactively modified parameters } \\
\hline SL & 260 & 267,0 & 267,8 & 267,8 & 267,8 & 267,8 & 267,8 & 266,0 & 267,0 \\
\hline LW & 49,8 & 49,8 & 58,0 & 57,5 & 57,2 & 57,2 & 57,2 & 57,2 & 57,2 \\
\hline BG & 216,4 & 216,4 & 251,9 & 250,0 & 246,5 & 246,9 & 247,2 & 247,2 & 247,2 \\
\hline IUG & 194,6 & 191,2 & 217,7 & 217,5 & 198,2 & 197,4 & 196,7 & 196,6 & 196,6 \\
\hline $\mathrm{HH}$ & 15,0 & 14,7 & 17,1 & 17,1 & 17,1 & 10,0 & 10,0 & 10,0 & 10,0 \\
\hline HW & 49,4 & 49,4 & 57,4 & 57,3 & 57,3 & 57,3 & 60,0 & 60,0 & 60,0 \\
\hline $\mathrm{HC}$ & 5,3 & 4,9 & 5,0 & 5,0 & 5,0 & 4,9 & 4,9 & 9,0 & 9,0 \\
\hline TS & 13,9 & 13,9 & 16,2 & 16,2 & 16,2 & 16,2 & 16,2 & 16,2 & 10,0 \\
\hline TT & 21,7 & 21,9 & 25,5 & 25,5 & 24,9 & 25,1 & 25,1 & 25,1 & 29,0 \\
\hline \multicolumn{10}{|c|}{ Outcome modified parameters } \\
\hline BL & 258 & 259,7 & 260,6 & 260,6 & 260,6 & 260,9 & 260,9 & 260,9 & 262,0 \\
\hline BUG & 133,0 & 133,0 & 154,7 & 153,4 & 150,0 & 150,5 & 150,8 & 150,8 & 150,9 \\
\hline BWC & 83,5 & 83,5 & 97,3 & 96,6 & 96,5 & 96,4 & 96,4 & 96,4 & 96,3 \\
\hline BWL & 82,4 & 82,4 & 96,0 & 95,4 & 95,2 & 95,2 & 95,2 & 95,2 & 95,2 \\
\hline IWC & 49,0 & 49,0 & 57,0 & 57,0 & 57,2 & 57,4 & 57,5 & 57,5 & 57,5 \\
\hline IWL & 48,3 & 48,3 & 56,2 & 56,2 & 56,4 & 56,6 & 56,7 & 56,7 & 56,7 \\
\hline $\mathrm{SHC}$ & 134,3 & 137,0 & 145,1 & 145,1 & 140,1 & 140,7 & 140,4 & 140,4 & 140,4 \\
\hline EW & 25,1 & 25,1 & 29,3 & 29,2 & 29,3 & 29,3 & 30,6 & 30,6 & 30,6 \\
\hline TL & 74,5 & 77,2 & 77,2 & 77,2 & 73,9 & 74,5 & 74,8 & 74,8 & 75,8 \\
\hline$A C$ & 11,3 & 10,7 & 12,5 & 12,5 & 12,2 & 6,8 & 6,7 & 6,7 & 6,7 \\
\hline AW & 32,3 & 33,1 & 38,6 & 38,5 & 39,3 & 39,6 & 39,7 & 39,7 & 39,7 \\
\hline
\end{tabular}

The dimensional parameters of the last, both the interactively modified parameters and the outcome parameters have different values on successive steps of modification. For comparing on a common basis the range of variations (increase or decrease) for each parameter, following calculus has been considered:

$\mathrm{Di}=(\mathrm{Pi} / \mathrm{Pi}-1-1) * 100(\%),(1)$

Where:

i -step of modification, i = 1, 2, 3, 4, 5, 6, 7, 8, 9

Di -increase or decrease of modified parameter on step i,, in \%

$\mathrm{Pi}$-value of modified parameter on step $\mathrm{i}$, in $\mathrm{mm}$

Pi-1 - value of modified parameter on step i-1 (previous step), in mm 
Table 2

Increase or decrease for interactively modified parameters and outcome parameters (empirically method)

\begin{tabular}{|c|c|c|c|c|c|c|c|c|c|}
\hline $\begin{array}{l}\text { Parameters } \\
\text { of the last }\end{array}$ & $\begin{array}{l}\text { 1st step of } \\
\text { modification- } \\
\text { on SL (\%) }\end{array}$ & $\begin{array}{l}\text { 2nd step of } \\
\text { modification- } \\
\text { on LW (\%) }\end{array}$ & $\begin{array}{l}\text { 3rd step of } \\
\text { modification- } \\
\text { on BG (\%) }\end{array}$ & $\begin{array}{l}\text { 4th step of } \\
\text { modification- } \\
\text { on IUG (\%) }\end{array}$ & $\begin{array}{l}\text { 5th step of } \\
\text { modification- } \\
\text { on } \mathrm{HH}(\%)\end{array}$ & $\begin{array}{l}\text { 6th step of } \\
\text { modification- } \\
\text { on HW (\%) }\end{array}$ & $\begin{array}{l}\text { 7th step of } \\
\text { modification- } \\
\text { on HC (\%) }\end{array}$ & $\begin{array}{l}\text { 8th step of } \\
\text { modification- } \\
\text { on TS (\%) }\end{array}$ & $\begin{array}{l}\text { 9th step } \\
\text { modifice } \\
\text { on TT (\% }\end{array}$ \\
\hline \multicolumn{10}{|c|}{ Interactively modified parameters } \\
\hline SL & 3,65 & 0,30 & 0,00 & 0,00 & 0,00 & 0,00 & $-0,67$ & 0,38 & 0,00 \\
\hline LW & 0,00 & 16,47 & $-0,86$ & $-0,52$ & 0,00 & 0,00 & 0,00 & 0,00 & 0,00 \\
\hline BG & 0,00 & 16,40 & $-0,75$ & $-1,40$ & 0,16 & 0,12 & 0,00 & 0,00 & 0,00 \\
\hline IUG & $-1,75$ & 13,86 & $-0,09$ & $-8,87$ & $-0,40$ & $-0,35$ & $-0,05$ & 0,00 & 0,00 \\
\hline $\mathrm{HH}$ & $-2,00$ & 16,33 & 0,00 & 0,00 & $-41,52$ & 0,00 & 0,00 & 0,00 & 0,00 \\
\hline HW & 0,00 & 16,19 & $-0,17$ & 0,00 & 0,00 & 4,71 & 0,00 & 0,00 & 0,00 \\
\hline $\mathrm{HC}$ & $-7,55$ & 2,04 & 0,00 & 0,00 & $-2,00$ & 0,00 & 83,67 & 0,00 & 0,00 \\
\hline TS & 0,00 & 16,55 & 0,00 & 0,00 & 0,00 & 0,00 & 0,00 & $-38,27$ & 0,00 \\
\hline TT & 0,92 & 16,44 & 0,00 & $-2,35$ & 0,80 & 0,00 & 0,00 & 15,54 & $-13,79$ \\
\hline \multicolumn{10}{|c|}{ Outcome parameters } \\
\hline$B L$ & 3,55 & 0,35 & 0,00 & 0,00 & 0,12 & 0,00 & 0,00 & 0,42 & 0,00 \\
\hline BUG & 0,00 & 16,32 & $-0,84$ & $-2,22$ & 0,33 & 0,20 & 0,00 & 0,07 & 0,00 \\
\hline BWC & 0,00 & 16,53 & $-0,72$ & $-0,10$ & $-0,10$ & 0,00 & 0,00 & $-0,10$ & 0,00 \\
\hline BWL & 0,00 & 16,50 & $-0,63$ & $-0,21$ & 0,00 & 0,00 & 0,00 & 0,00 & 0,00 \\
\hline IWC & 0,00 & 16,33 & 0,00 & 0,35 & 0,35 & 0,17 & 0,00 & 0,00 & 0,00 \\
\hline IWL & 0,00 & 16,36 & 0,00 & 0,36 & 0,35 & 0,18 & 0,00 & 0,00 & 0,00 \\
\hline SHC & 2,01 & 5,91 & 0,00 & $-3,45$ & 0,43 & $-0,21$ & 0,00 & 0,00 & 0,00 \\
\hline EW & 0,00 & 16,73 & $-0,34$ & 0,34 & 0,00 & 4,44 & 0,00 & 0,00 & 0,00 \\
\hline TL & 3,62 & 0,00 & 0,00 & $-4,27$ & 0,81 & 0,40 & 0,00 & 1,34 & 0,00 \\
\hline$A C$ & $-5,31$ & 16,82 & 0,00 & $-2,40$ & $-44,26$ & $-1,47$ & 0,00 & 0,00 & 0,00 \\
\hline AW & 2,48 & 16,62 & $-0,26$ & 2,08 & 0,76 & 0,25 & 0,00 & 0,00 & 0,00 \\
\hline
\end{tabular}

Di variations are calculated against the previously obtained values; thus, the dependencies between two successive modified lasts can be progressively noticed and quantified. Additionally, after the final iteration is performed (corresponding to the 9th step), the variation is calculated with the same relation (Eq. 1), by comparing final obtained parameters with parameters of the reference last.

Because the order of modifying the last was empirically established, a mathematical method is proposed by the authors using a DSM matrix. The right method will be the one in which the last's parameters are closer to the scanned foot.

DSM matrix design was firstly described by Yassine in 1999, being developed and applied later in many fields (Mihai A. et al. 2009). In this type of analysis, three steps are followed:

1. The product is decomposed in elements and the relationships and connections between them are established;

2. The identified elements are written in the same order in a matrix. The connection between elements is marked inside the matrix;

3. The matrix is transformed using special algorithms in a low triangular shape by arranging rows such that the marked points are located close to the diagonal of the matrix. A specialized software facilitates and simplifies the procedure.

In our case, the algorithm used is the one A. Kusiak et al., developed in 1994 and available at: http://css.engineering.uiowa.edu/ ankusiak/processmodel.html was used.

Based on the obtained results, the initial last will be modified respecting the order given by the DSM matrix. The results can be seen in the table below: 
Table 3

Increase or decrease for interactively modified parameters and outcome parameters (DSM method)

\begin{tabular}{|c|c|c|c|c|c|c|c|c|c|}
\hline $\begin{array}{l}\text { Parameters } \\
\text { of the last }\end{array}$ & $\begin{array}{l}\text { 1st step of } \\
\text { modification- } \\
\text { on SL (\%) }\end{array}$ & $\begin{array}{l}\text { 2nd step of } \\
\text { modification- } \\
\text { on } L W(\%)\end{array}$ & $\begin{array}{l}\text { 3rd step of } \\
\text { modification- } \\
\text { on BG (\%) }\end{array}$ & $\begin{array}{l}\text { 4th step of } \\
\text { modification- } \\
\text { on IUG (\%) }\end{array}$ & $\begin{array}{l}\text { 5th step of } \\
\text { modification- } \\
\text { on } \mathrm{HH}(\%)\end{array}$ & $\begin{array}{l}\text { 6th step of } \\
\text { modification- } \\
\text { on HW (\%) }\end{array}$ & $\begin{array}{l}\text { 7th step of } \\
\text { modification- } \\
\text { on } \mathrm{HC}(\%)\end{array}$ & $\begin{array}{l}\text { 8th step of } \\
\text { modification- } \\
\text { on TS (\%) }\end{array}$ & $\begin{array}{l}\text { 9th step } \\
\text { modifica } \\
\text { on TT (\% }\end{array}$ \\
\hline \multicolumn{10}{|c|}{ Interactively modified parameters } \\
\hline SL & 3,65 & 0,00 & 0,00 & 0,00 & 0,00 & $-0,67$ & 0,00 & 0,30 & 0,00 \\
\hline BG & 0,00 & 15,53 & $-9,20$ & 10,57 & 0,08 & 0,12 & $-0,04$ & $-0,08$ & 0,00 \\
\hline LW & 0,00 & 16,87 & $-0,34$ & 0,00 & 0,00 & 0,00 & 0,00 & 0,00 & 0,00 \\
\hline IUG & $-1,75$ & $-0,05$ & 1,78 & 1,90 & $-0,55$ & $-0,10$ & $-0,20$ & 0,46 & 0,00 \\
\hline $\mathrm{HH}$ & $-2,00$ & 0,00 & $-0,68$ & 0,00 & $-31,51$ & 0,00 & 0,00 & 0,00 & 0,00 \\
\hline $\mathrm{HC}$ & $-7,55$ & 0,00 & 0,00 & 0,00 & 0,00 & 83,67 & 0,00 & 0,00 & 0,00 \\
\hline HW & 0,00 & 0,00 & $-0,20$ & 0,00 & 0,00 & 0,00 & 21,70 & 0,00 & 0,00 \\
\hline TS & 0,00 & 0,00 & 0,00 & 0,00 & 0,00 & 0,00 & 0,00 & $-28,06$ & 0,00 \\
\hline TT & 0,92 & 0,46 & 4,09 & 0,00 & 0,87 & 0,00 & 0,00 & 10,39 & $-1,96$ \\
\hline \multicolumn{10}{|c|}{ Outcome parameters } \\
\hline BL & 3,55 & 0,04 & 0,00 & 0,00 & 0,04 & 0,00 & 0,00 & $-0,15$ & 0,00 \\
\hline BUG & 0,00 & 16,84 & $-7,34$ & 9,10 & 0,06 & 0,19 & 0,00 & $-0,13$ & 0,00 \\
\hline BWC & 0,00 & 13,29 & $-12,16$ & 13,12 & $-0,11$ & 0,00 & 0,00 & 0,00 & 0,00 \\
\hline BWL & 0,00 & 13,59 & $-12,29$ & 13,28 & 0,00 & 0,00 & 0,00 & 0,00 & 0,00 \\
\hline IWC & 0,00 & 0,00 & $-0,20$ & 0,00 & 0,00 & 0,00 & 0,00 & 2,25 & 0,00 \\
\hline IWL & 0,00 & 0,00 & $-0,21$ & 0,00 & 0,00 & 0,00 & 1,87 & 0,41 & 0,00 \\
\hline SHC & 2,01 & 0,00 & 1,17 & $-0,65$ & 0,15 & 0,00 & 0,00 & 0,00 & 0,00 \\
\hline EW & 0,00 & 0,00 & $-0,40$ & 0,00 & 0,00 & 0,00 & 20,40 & 0,00 & 0,00 \\
\hline $\mathrm{TL}$ & 3,62 & 0,00 & 0,00 & 4,66 & 0,50 & 0,12 & 0,00 & 0,74 & 0,00 \\
\hline$A C$ & $-5,31$ & 0,00 & 1,87 & 0,92 & $-33,64$ & 0,00 & 0,00 & 0,00 & 0,00 \\
\hline AW & 2,48 & 0,00 & $-2,11$ & $-0,62$ & 0,62 & 0,00 & 1,24 & $-0,31$ & 0,00 \\
\hline
\end{tabular}

The results of the two methods, empirically one and DSM method are presented in the table below.

Table 4

Centralized results of two studied cases

\begin{tabular}{|c|c|c|c|}
\hline \multicolumn{2}{|l|}{1 st case } & \multicolumn{2}{|l|}{ 2nd case } \\
\hline $\begin{array}{l}\text { The order of empirically } \\
\text { modified parameters }\end{array}$ & $\begin{array}{l}\text { Variation between final modified last and } \\
\text { reference last (\%) }\end{array}$ & $\begin{array}{l}\text { The order of DSM modified } \\
\text { parameters }\end{array}$ & $\begin{array}{l}\text { Variation between final modified last and } \\
\text { reference last (\%) }\end{array}$ \\
\hline SL & 3,65 & SL & 3,26 \\
\hline LW & 14,86 & $B G$ & 16,08 \\
\hline BG & 14,23 & LW & 16,47 \\
\hline IUG & 1,03 & IUG & 1,44 \\
\hline $\mathrm{HH}$ & $-33,33$ & $\mathrm{HH}$ & $-33,33$ \\
\hline HW & 21,46 & $\mathrm{HC}$ & 69,81 \\
\hline $\mathrm{HC}$ & 69,81 & HW & 21,46 \\
\hline TS & $-28,06$ & TS & $-28,06$ \\
\hline $\mathrm{TT}$ & 15,21 & $\mathrm{TT}$ & 15,21 \\
\hline
\end{tabular}


Comparing the results obtained in both cases, the empirical method and the DSM method, lower deviation from the initial last are obtained in the user defined order: $\mathrm{SL}>\mathrm{LW}>\mathrm{BG}>\mathrm{IUG}>\mathrm{HH}>\mathrm{HW}>\mathrm{HC}>\mathrm{TS}>\mathrm{TT}$. Research is recommended to continue, for testing another order for the parameters.

All successive modifications on the empirical method are made considering the foot's anthropometric measurements and the dimensional parameters of the reference last (Table 5). The result is an adapted last to the subject's foot (Fig. 8).

Table 5

Correspondences among the foot, the initial last and the modified last

\begin{tabular}{|c|c|c|c|c|c|}
\hline \multirow[t]{2}{*}{ Anthropometric parameter on foot } & \multicolumn{2}{|c|}{ Measurements } & \multirow[t]{2}{*}{ Constructive parameter on last } & \multicolumn{2}{|l|}{ Measurements } \\
\hline & $\begin{array}{l}\text { Left foot } \\
(\mathrm{mm})\end{array}$ & $\begin{array}{l}\text { Right foot } \\
(\mathrm{mm})\end{array}$ & & $\begin{array}{l}\text { Reference Last } \\
(\mathrm{mm})\end{array}$ & $\begin{array}{l}\text { Modified Last } \\
(\mathrm{mm})\end{array}$ \\
\hline \multirow[t]{2}{*}{ Foot Length, FL } & 257.6 & 259.2 & Stick Length, SL & 260.0 & 267.0 \\
\hline & & & Bottom Length, BL & 258 & 262 \\
\hline Foot Ball Width, FBW & 105.3 & 104.2 & Ball Width Linear, BWL & 83.5 & 96.3 \\
\hline Foot Lateral Width, FLW & 58.0 & 57.4 & Lateral Width, LW & 49.8 & 57.2 \\
\hline Foot Arch Width, FAW & 33.0 & 32.0 & Arch Width, AW & 32.3 & 39.7 \\
\hline Foot Heel Width, FHW & 68.5 & 67.6 & Heel Width, HW & 49.4 & 60 \\
\hline \multirow[t]{4}{*}{ Foot Ball Girth, FBG } & 247.3 & 245.5 & Ball Girth, & 216.4 & 247.2 \\
\hline & & & $B G=B U G+B W C$ & 133.0 & 150.9 \\
\hline & & & Ball Upper Girth, BUG & 83.4 & 96.3 \\
\hline & & & Ball Width Curved, BWC & & \\
\hline \multirow[t]{4}{*}{ Foot Instep Girth, FIG } & 240.2 & 239.6 & Instep Circumferences, & 243.6 & 254.1 \\
\hline & & & $I C=I U G+I W C$ & 194.6 & 196.6 \\
\hline & & & Instep Upper Girth, IUG & 49 & 57.5 \\
\hline & & & Instep Width Curved, IWC & & \\
\hline Foot Height to 1st Toe, FHT & 20.7 & 24.4 & Toe Thickness, TT & 21.7 & 25.0 \\
\hline
\end{tabular}

Table 6

Technological

dimensional

parameters of

last

\begin{tabular}{|lll|}
\hline Parameters & \multicolumn{2}{l|}{ Measurements } \\
\cline { 2 - 3 } & $\begin{array}{l}\text { Reference Last } \\
(\mathbf{m m})\end{array}$ & $\begin{array}{l}\text { Modified Last } \\
(\mathbf{m m})\end{array}$ \\
\hline Heel Height, HH & 15 & 10 \\
\hline Instep Width Linear, IWL & 48,3 & 56,7 \\
\hline Short Heel Curved, SHC & 134,3 & 140,4 \\
\hline Toe Spring, TS & 13.9 & 10 \\
\hline Toe Length, TL & 74.5 & 75.8 \\
\hline Entrance Width, EW & 25.1 & 30.6 \\
\hline Heel Counter, HC & 5.3 & 9 \\
\hline Arch Curve, AC & 1.13 & 0.67 \\
\hline
\end{tabular}

\section{Discussions}


The relations between human foot and last is critical for designing new footwear, lasts or footwear bottom components as insoles, soles, orthoses, etc., as well as their manufacturing (Chung-Shing W., 2010). Lasts give the fitting volume and the inner dimensions of footwear. A last designed on empirical trials, without a scientific basis towards the consumer's foot specific conformation, will lead to a less comfortable product (Lee Au E.Y. and Goonetilleke R.S., 2007). Furthermore, inappropriate footwear could cause irreversible changes on foot and/or on gait patterns (Wegener et al. 2011). The concept of shoe-last tailored to support foot's modification during human body locomotion is not precisely and finally defined yet. Complete customization of lasts and footwear is still under development, but some promising results have demonstrated clear good practices of how CAD/CAM systems for simulations and modelling can be employed to bring innovative solutions in the footwear industry (Azariadis P. et.al. 2010, Ruperez M.J. et.al. 2010, Xiao M. et.al. 2011). Further research is needed to assess entirely customized lasts and customized footwear. The lack of information in this area still determines the designers to select the last just based on empirical approaches gained from previous experiences (Wang Z. et al, 2009).

The described method, as well as the developed methodology for analyzing the final results of the modelling process, could be replicated and applied for any new study case. In order to obtain the modified last, five working stages have been followed up: 1) scanning the foot; 2) positioning the anatomical points on foot; 3) measuring/calculating the main anthropometric measurements; 4) comparing the foot against the reference last; 5) modifying the last towards the foot shape.

The studied case refers to a subject (47-year-old, female, diagnosed with arthritis and incipient stages of Hallux-Valgus) having visibly identified foot problems that ask for a careful interpretation of the design features based on anthropometric data, biomechanics and orthopaedic requirements. Several initial stages of structural modification related with arthritic feet have been identified on this subject, especially in the forefoot area.

The obtained data from 3D interactive modifications on dimensional parameters follows up nine successive steps. Each step is based on the results obtained in the previous step. When one parameter is modified, the entire range of the studied parameters is collected. While the modelling process advances, there are determined paired relationships among sets of parameters that characterize the shape of last at each step of modification.

The dimensional parameters of the last, both the interactively modified parameters and the outcome parameters have different values on successive steps of modification.

Each modification on a parameter brings changes to the other parameters. The designer has to follow each change, so that at the end, the last will be proper to the subject's foot. This research has indicated that modifying last's parameters are not enough for designing a customized last, the relationship between parameter has to be taken into account. The limitation of this paper given by the fact that some foot area could be tightened while wearing a footwear product, and to know if these are acceptable, the subject has to wear a shoe designed on these specific lasts.

\section{Conclusions}

This research follows up an extended and integrated application on combining CAD techniques for 3D shoe-last modelling with 3D foot Scanning and measuring procedures. Both 3D scanning and 3D virtual modelling in the practice of designing fully customized lasts for special purposes are analyzed and presented as grounded related results for further innovation and development on software applications in the footwear industry. The present study brings together the modern scanning technique with the new methodology for modifying a reference last through interactive 3D modelling. Thus, it aims to go deeply into re-designing process of functional lasts based on anthropometric data obtained from 3D foot scanning. This research emphasizes the necessity of reuniting various modelling methods and scanning techniques into a new common standardized approach that should make the data transforming process more easily and precisely.

\section{Declarations}

Ethics approval Not applicable.

Consent to participate All authors have approved to participate.

Consent for publication The manuscript is approved by all authors for publication.

Conflict of interest The authors declare that they have no conflict of interest.

\section{References}

1. Andrews K. L., (2011), The at-risk foot: What to do before and after amputation, Journal of Vascular Nursing, Volume 29, Issue 3 , Pages $120-123$

2. Azariadis P., Moulianitis V., Melis J.O., Alemany S., Gonzalez J., Jong P., Dunias P., Zande M., Brands D., (2010), An innovative virtual-engineering system for supporting integrated footwear design, International Journal of Intelligent Engineering Informatics, Vol. 1, Issue 1, pp. 53-74

3. Bertram H., (2011), Practical operation of last construction, Footwear Science, Volume 3, Number S1, pp. 10-11

4. Chantelau, E., Gede, A. (2002), Foot dimensions of elderly people with and without diabetes mellitus-a data basis for shoe design, Gerontology, 48(4), pp. 241-244

5. Cheng F.T., Perng D.B. (1999), A systematic approach for developing a foot size information system for shoe last design, International Journal of Industrial Ergonomics, Vol. 25, Issue 2, pp. 171-185

6. Chung-Shing W., (2010), An analysis and evaluation of fitness for shoe lasts and human feet, Computers in Industry, Vol. 61, Issue 6, pp. 532-540 
7. Dahmen R., Haspels R., Koomen B., Hoeksma A.F., (2001), Therapeutic Footwear for the Neuropathic Foot: An algorithm, Diabetes Care, vol. 24 no. 4 ,705709

8. Dumitras ,Cozminca I., (2008), Large Deformation Modeling Applied to the Sheet Metal Electromagnetic Forming, $9^{\text {th }}$ ASME Engineering Systems Design and Analysis Conference, ESDA 2008, ISBN 0-7918-3827-7, Haifa , Israel

9. Ionesi D., Ciobanu L., Sarghie B., (2014) E-Learning Application for a better understanding of shoes 3D modeling, 10th International Scientific Conference eLSE, pages 196, ISSN 2360-2198.

10. Jones, J. and Wimpenny, D. (2009), Customised rapid manufactured parts: Technology and case studies from the custom-fit project, in Procc. of 20thInternational Solid Freeform Fabrication Symposium, Austin, TX, USA, pp. 662-672

11. Lee Au E.Y., Goonetilleke R.S., (2007), A qualitative study on the comfort and fit of ladies' dress shoes, Applied Ergonomics 38, pp.687-696

12. Lee Au E.Y., Goonetilleke R.S., Witana C.P., Xiong S., (2011), A methodology for determine the allowances for fitting footwear, International Journal of Human Factors Modelling and Simulation (IJHFMS), Vol. 2, No. 4, pp. 341-366

13. Liu S., Cui Y., Sanchez S., Stricker D., (2011), Foot scanning and deformation estimation using time-of-flight cameras, Footwear Science, Vol. 3, Number S1, 598-599

14. Luximon A., Luximon Y.,(2009), Shoe-last design innovation for better shoe fitting, Journal Computers in Industry, Vol. 60 Issue 8 , pp. $621-628$

15. Luximon A., Zhang Y., Luximon Y., Xiao M., Luximon A., Zhang Y., Luximon Y, Xiao M., (2012), Sizing and grading for wearable products, Computer- Aided Design, Vol. 44, Issue 1, pp. 77-84

16. Mihai A., Păştină M., Harnagea M.C., Rusu B., Volocariu, Dragomir A., Ichim M., Metode utilizate în conceptualizarea şi dezvoltarea produselor de încă/ţăminte, Editura Performantica, laşi, 2009, ISBN 9789737306487

17. Mochimaru M., Kouchi M., (2011), Free deformation method and its application to grading shoe lasts, Footwear Science, Volume 3, Number S1, pp. 112113

18. Mochimaru M., Kouchi M., Dohi M., (2000), Analysis of 3D human foot forms using the FFD method and its application in grading shoe last, Ergonomics, Vol. 43(9), pp. 1301-1313

19. Nikolaidou M.E., Boudolos K.D., (2006), A footprint-based approach for the rational classification of foot types in young schoolchildren, The Foot no. 16, pp. 82-90.

20. Pastina M., Mihai A., (2010), 3D Modelling and Rapid Prototyping of Lasts Used to Obtain Special Footwear for Patients with Arthritis, Proceedings of the 3rd International Conference on Advanced Materials and Systems, ICAMS2010, pp. 283-288, http://www.scopus.com/inward/record.url?eid=2-s2.079959852703\&partnerID=40\&md5=cf53e5d718e96c56ebe34e96f323ce14

21. Pastina M., Mihai A., (2011), 3D modelling of customized lasts, Proceedings of ModTech International Conference - Modern Technologies, Quality and Innovation - New face of TMCR, Vol. II, pp. 825-828

22. Pastina M., Mihai A., Bilalis N., (2012), Finite element analysis for insole-sole prototypes, Proceedings of the 4th International Conference on Advanced Materials and Systems, ICAMS 2012, pp. 359-364, http://www.scopus.com/inward/record.url?eid=2-s2.084888235803\&partnerID=40\&md5=a7fa0108267a69b149b79d8b2fa572f4

23. Reel S., Rouse S., Vernon W., Doherty P., (2010), Reliability of a two-dimensional footprint measurement approach, 2010, Vol.50, issue 3, pp. $113-118$.

24. Rupérez M.J., Monserrat C., Alemany S., Juan M.C., Alcañíz M., (2010), Contact model, fit process and, foot animation for the virtual simulator of the footwear comfort, Computer- Aided Design, Vol. 42, Issue 5, pp. 425-431

25. Sarghie, Costea M., Mihai A., (2013), 3D modelling of shoe lasts using templates based on anthropometrical measurements of the foot - case study, Leather and Footwear Journal, vol. 13, no. 3, pp. 221-234

26. Sederberg, T.W., (1986), Free-From Deformation of Solid Geometric Models, Proceedings of ACM şi GGRAPH'86 in Computers \& Graphics, Vol. 20(4), pp. 151-160

27. Sikyung K., Mazumder M.M.G., Park S. J.A, (2007), Conformal Mapping Approach for Shoe Last Design, in Frontiers in the Convergence of Bioscience and Information Technologies, pp. $512-518$

28. Telfer S., Woodburn J., (2010), The use of 3D surface scanning for the measurement and assessment of the human foot, Journal of Foot and Ankle Research, pp. 3-19

29. Uccioli L., (2006), The Role of Footwear in the Prevention of Diabetic Foot Problems, The Diabetic Foot Contemporary Diabetes, pp. 523-541, D0I 10.1007/978-1-59745-075-1_25

30. Wang Z., Shang X., Wang X., (2009), Research of the Virtual Prototyping Technology Based on Laser Processing, Applied Mechanics and Materials, Vols. 16-19, pp. 871-875

31. Wang J., Zhang H., Lu G., Liu Z., (2011), Rapid Parametric Design Methods for Shoe-Last Customization, The International Journal of Advanced Manufacturing Technology, Vol. 54, Issue 1-4, pp. 173-186

32. Wegener C., Hunt A.E., Vanwanseele B., Burns J., Smith R.M., (2011), Effect of children's shoes on gait: a systematic review and meta-analysis, Journal of Foot and Ankle Research, Vol. 4:3, DOI:10.1186/1757-1146-4-3

33. Williams A.E., Davies S., Graham A., Dagg A., Longrigg K., Lyons C, Bowen C., (2011) Guidelines for the Management of the Foot Health Problems Associated with Rheumatoid Arthritis, Musculoskeletal Care, Vol. 9, Issue 2, pp. 86-92

34. Witana C.P., Xiong S., Zhao J., Goonetilleke R.S., (2006), Foot measurements from three-dimensional scans: A comparison and evaluation of different methods, International Journal of Industrial Ergonomics, Vol. 36, Issue 9, pp.789-807 
35. Xiao M., Zhang Y., Luximon A., (2011), A shoe-last selection system based on fit rating, International Journal of Human Factors Modelling and Simulation, Vol. 2, Issue 4, pp. 327-340

36. Xiong S., Goonetilleke R.S., Witana C.P., Lee Au E.Y., (2008), Modelling foot height and foot shape-related dimensions, Ergonomics, Vol.51, Issue 8, pp. $1272-1289$

37. ***, INFOOT- Foot Measurement, available on http://www.iwl.jp

38. http://css.engineering.uiowa.edu/ ankusiak/process-model.html

\section{Figures}
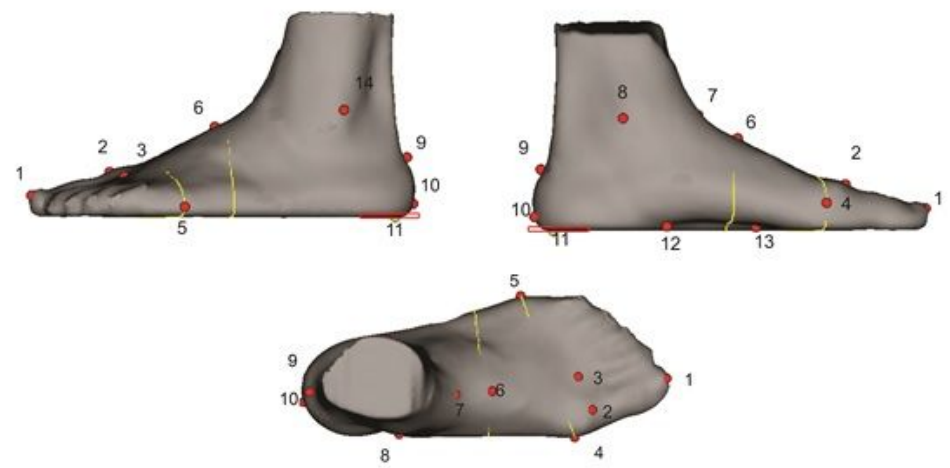

Figure 1

There are 26-foot landmarks suggested by INFOOT user manual. 1- Tip of 1st toe 2- Head of the 1st metatarsal bone 3- Head of the 2nd metatarsal bone 4Metatarsal tibiale - 1st metatarsal head 5- Metatarsal fibulare - 5th metatarsal head 6- Top of instep point 7- Junction point 8- Medial malleolus 9- Upper heel point 10-Extreme heel point 11-Landing point 12-Arch point 1 13-Arch point 2 14- Lateral malleolus

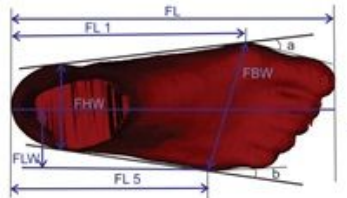

a)

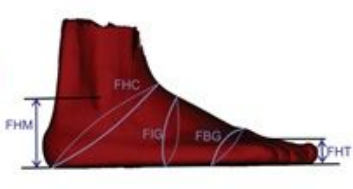

b)

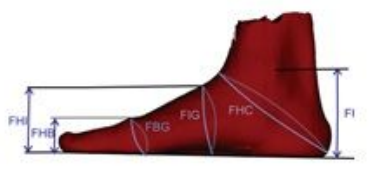

c)

Figure 2

Anthropometric measurements: a) upper view, b) lateral view, c) medial view

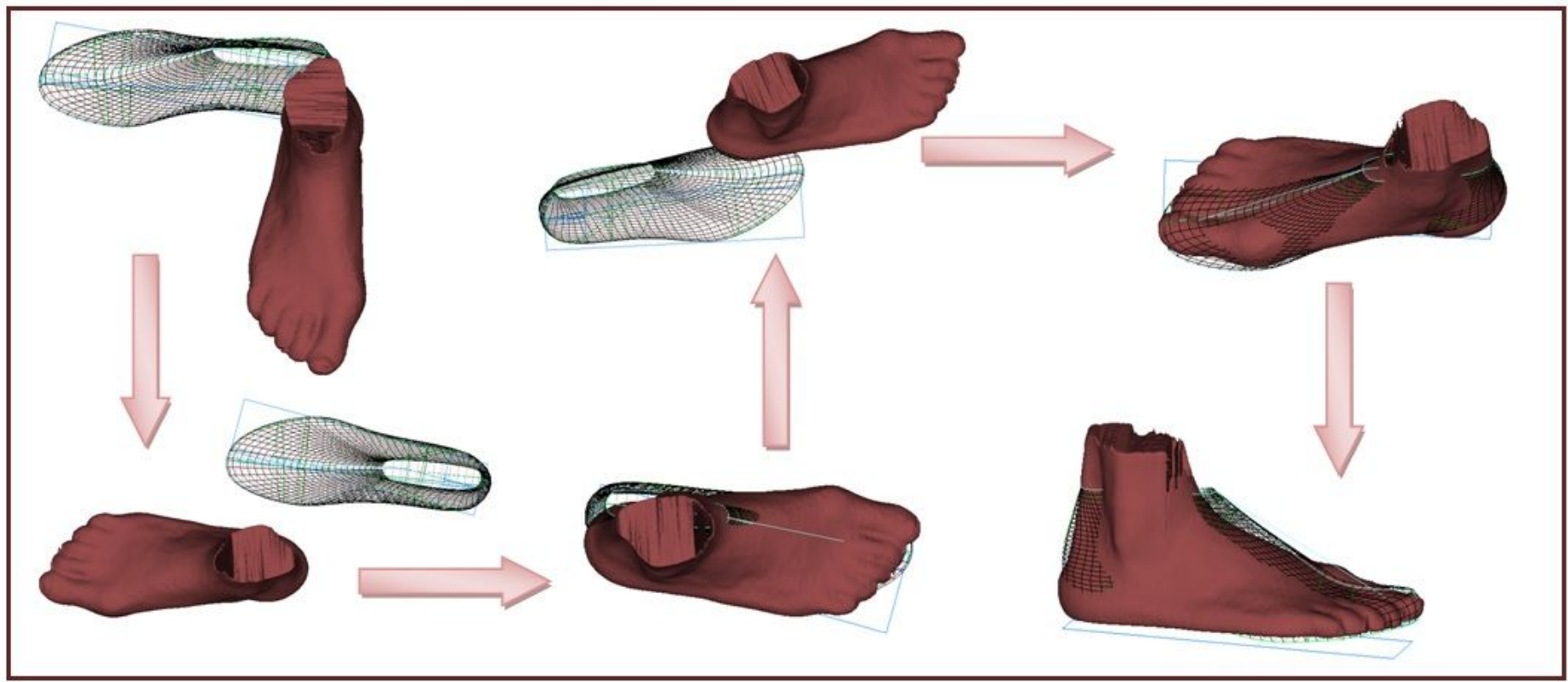

Figure 3 
Interactively aligning the foot to the reference last
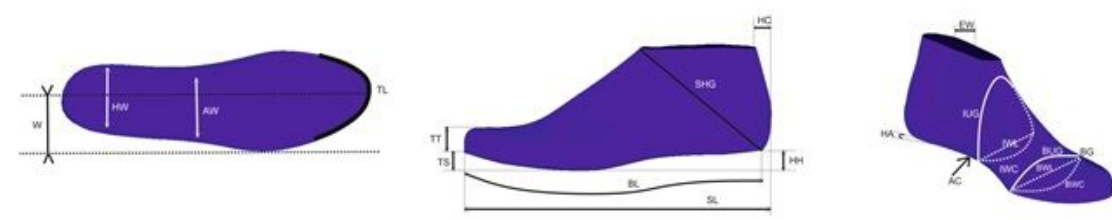

\section{Figure 4}

Illustrated methodology for measuring dimensional parameters of shoe-last

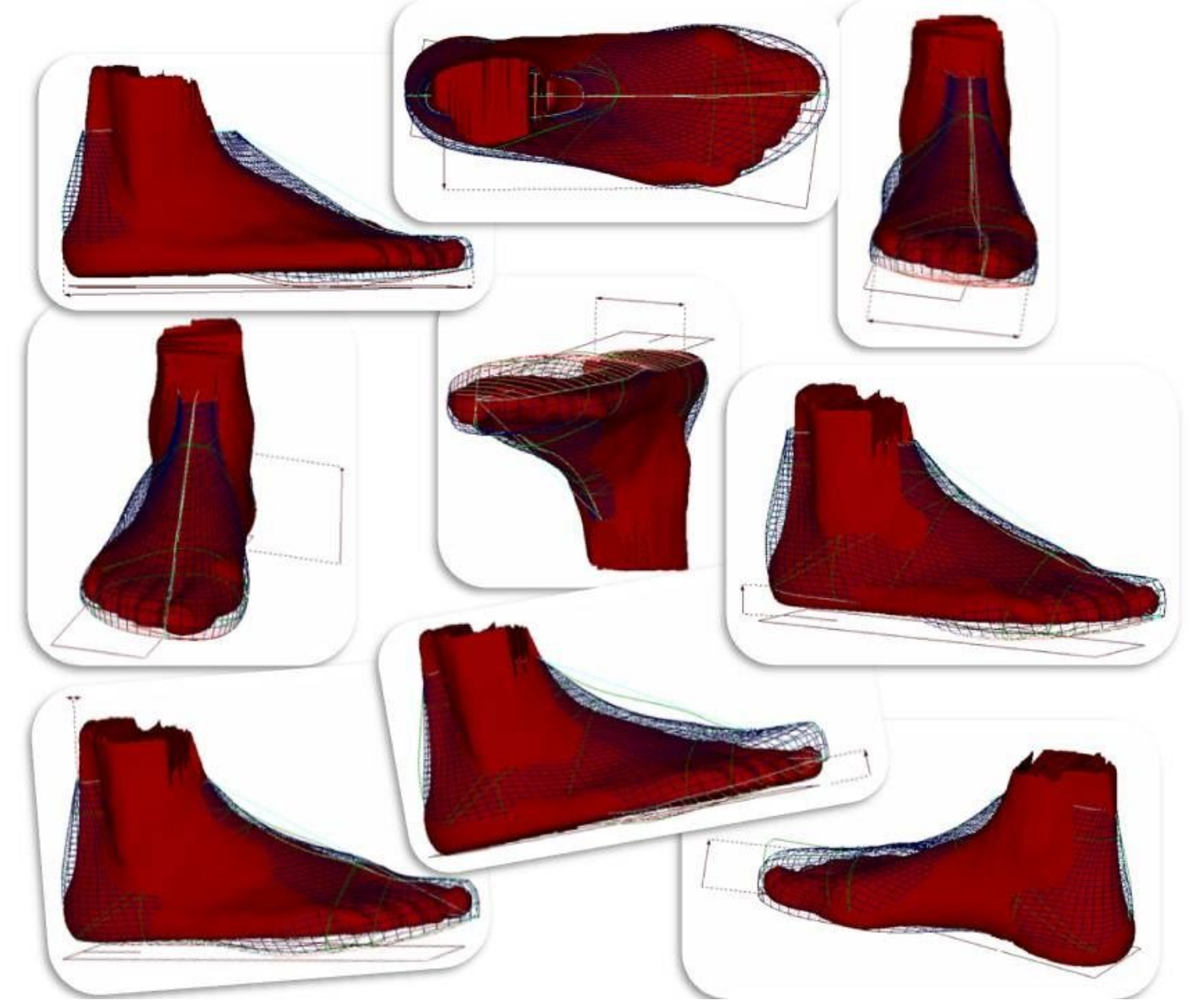

Figure 5

The nine-step methodology for modelling the last. 


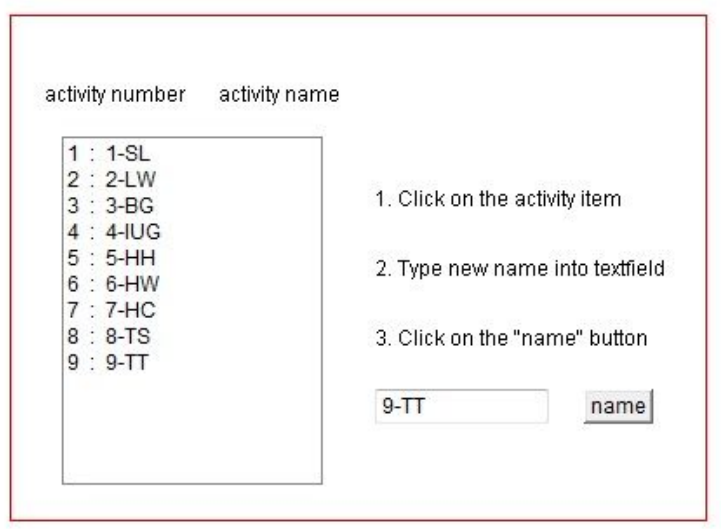

\begin{tabular}{llll} 
number & name & interaction calpulate \\
\hline
\end{tabular}

\section{Figure 6}

Establishing the matrix elements

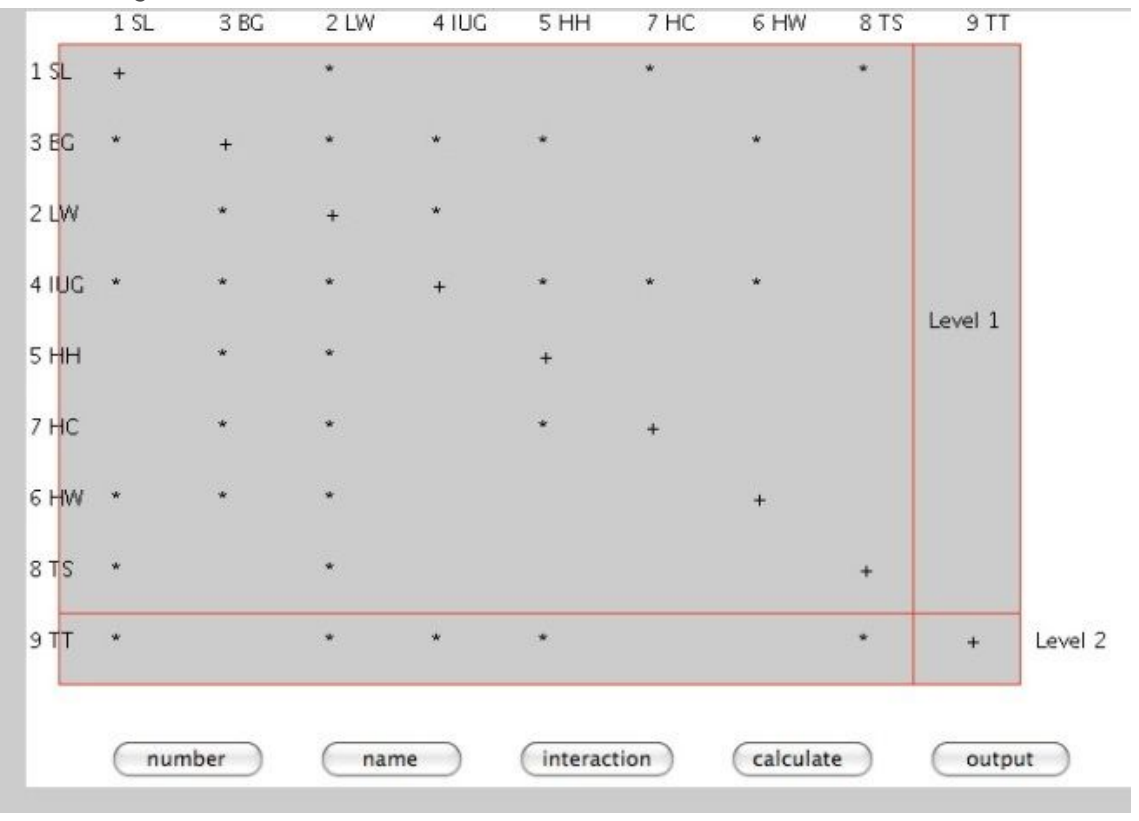

Figure 7

Generating the matrix

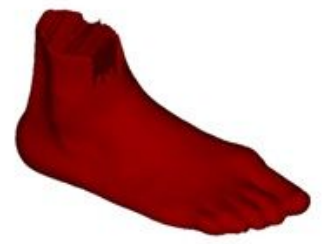

a)

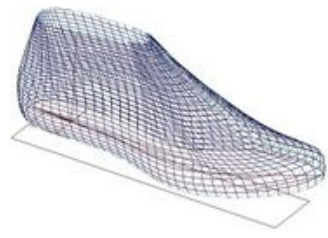

b)

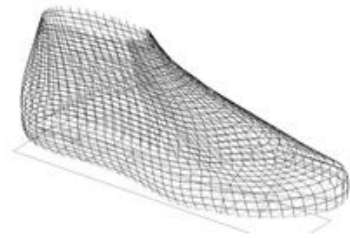

c)

Figure 8

Foot (a), initial last (b) and modified last (c) 